\title{
Spatiotemporal Trends of Elemental Carbon and Char/Soot Ratios in Five Sediment Cores from Eastern China Marginal Seas: Indicators of Anthropogenic Activities and Transport Patterns
}

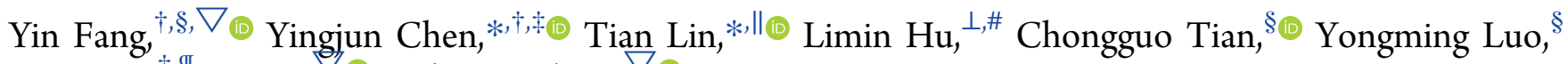

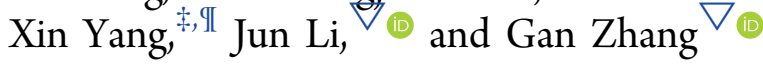

${ }^{\dagger}$ Key Laboratory of Cities’ Mitigation and Adaptation to Climate Change in Shanghai, College of Environmental Science and Engineering, Tongii University, Shanghai 200092, China

${ }^{\ddagger}$ Shanghai Institute of Pollution Control and Ecological Security, Shanghai 200092, China

${ }^{\S}$ Key Laboratory of Coastal Environmental Processes and Ecological Remediation, Yantai Institute of Coastal Zone Research, Chinese Academy of Sciences, Yantai 264003, China

"State Key Laboratory of Environmental Geochemistry, Guiyang Institute of Geochemistry, Chinese Academy of Sciences, Guiyang 550081, China

${ }^{\perp}$ Key Laboratory of Marine Sedimentology and Environmental Geology, First Institute of Oceanography, State Oceanic Administration, Qingdao 266061, China

\#Laboratory for Marine Geology, Qingdao National Laboratory for Marine Science and Technology, Qingdao 266061, China

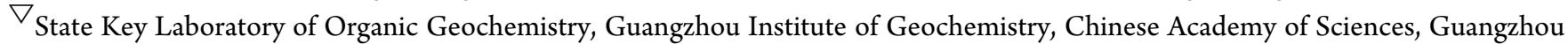
510640, China

"I Shanghai Key Laboratory of Atmospheric Particle Pollution and Prevention, Department of Environmental Science and Engineering, Fudan University, Shanghai 200433, China

\section{Supporting Information}

ABSTRACT: Elemental carbon (EC), the highly recalcitrant carbonaceous material released exclusively from fossil fuel combustion and biomass burning, is a preferred geochemical agent for evaluating anthropogenic activities. We investigated the spatiotemporal trends of EC and char/soot ratios (char and soot, the two subtypes of $\mathrm{EC}$, differ in formation mechanisms and physicochemical characteristics) in five sediment cores from eastern China marginal seas, spatially spanning from inshore coastal mud areas to offshore remote mud areas. The temporal profiles of EC depositional fluxes closely tracked socioeconomic development in China over the past $\sim 150$ years, with the most pronounced increasing trend beginning in the early 1980s, commensurate with the implementation of national policy of Reform and Open in 1978. The temporal EC profiles in China differed significantly from those in European/American countries, reflecting their different socioeconomic development stages. The spatiotemporal trends of char/soot ratios were also highly informative. Temporally, they decreased from bottom to subsurface layers,

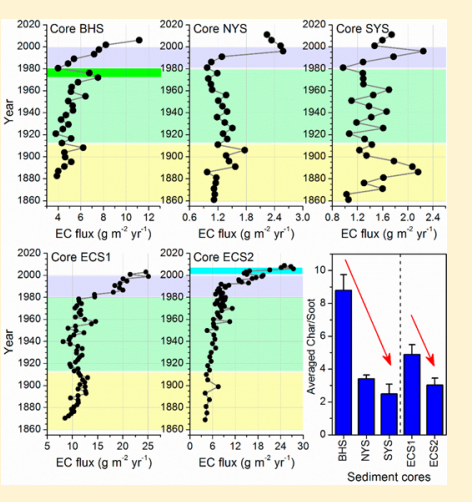
indicating the switch of China from an agricultural economy to an industrial economy during the 20th century. Spatially, they decreased from inshore to offshore areas, suggesting the differential transport patterns of EC among these sampling regimes.

\section{INTRODUCTION}

Elemental carbon (EC), sometimes termed black carbon (BC) or pyrogenic carbon $(\mathrm{PyC}),{ }^{1-3}$ is of great attention owing to its potential roles in global/regional carbon cycles, ${ }^{4}$ climate change, ${ }^{5}$ air quality, ${ }^{6}$ and public health. ${ }^{7}$ EC is characterized as a highly aromatic and recalcitrant carbon species released exclusively from incomplete burning of organic matter, including fossil fuels (e.g., coal and petroleum) and biomass. ${ }^{8}$ Despite its identified potential importance, EC is not a chemically singular entity with well-characterized properties but rather exists as a complex combustion continuum. ${ }^{2,9} \mathrm{EC}$ is an operational term, which means that its precise definition depends on the applied quantification methodology. ${ }^{2,9}$ In general, EC can be formed by two fundamentally different processes, which correspond to two subtypes, char and soot. ${ }^{10-13}$ Char is the partially combusted solid residue formed at low temperatures $\left(300-600{ }^{\circ} \mathrm{C}\right)$, retaining some chemistry and morphology of its parent precursors, with typical particle size distributions of $1-100 \mu \mathrm{m} .{ }^{10,13}$ By contrast, soot is

Received: January 3, 2018

Revised: $\quad$ May 17, 2018

Accepted: August 4, 2018

Published: August 5, 2018 


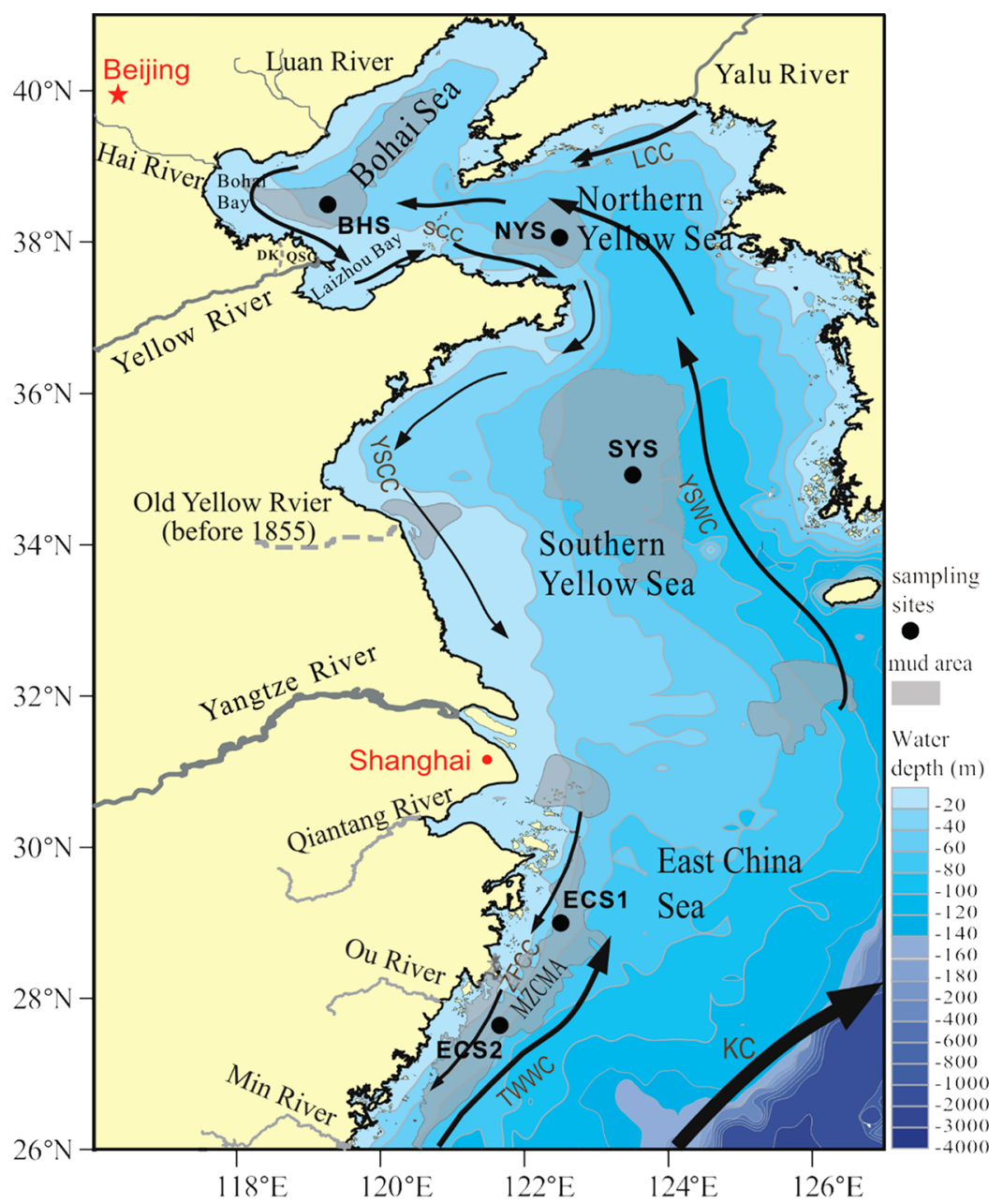

Figure 1. Map showing the study area and sampling sites. KC, Kuroshio current; TWWC, Taiwan warm current; ZFCC, Zhejiang-Fujian coastal current; YSCC, Yellow Sea coastal current; YSWC, Yellow Sea warm current; SCC, Shandong coastal current; LCC, Liaonan coastal current; MZCMA, Min-Zhe coastal mud area. Circulations and mud areas are modified from $\mathrm{Hu}$ et al. ${ }^{32}$ and $\mathrm{Li}$ et al. ${ }^{33}$.

comprised of submicrometer-sized particles of structurally grapelike clusters produced in flames from condensation of hydrocarbon radicals at higher temperatures $\left(>600{ }^{\circ} \mathrm{C}\right)$, and it does not maintain any morphology of its combusted parent precursors. ${ }^{10,13}$ Due to their distinct formation conditions (e.g., temperatures) and physicochemical properties (e.g., particle sizes and resultant transportability), the effective discrimination between char and soot in environments may provide further information revealing EC sources and transport pathways. ${ }^{10,11,14}$ For instance, Han et al. ${ }^{11}$ recently reported similar depositional fluxes of soot in northern and southern Lake Qinghai subbasins in the Tibetan Plateau but with distinct depositional fluxes for char, suggesting regional atmospheric soot deposition but local riverine char inputs.

The purely pyrogenic origin and postdepositional resistance against degradation makes EC an increasingly preferred geochemical agent for reconstructing historical impacts of anthropogenic activities (e.g., changing energy strategies and mitigation measures) regionally and/or globally. ${ }^{10,11,15-19}$ Such temporal EC trends can be reliably retrieved from undisturbed environmental archives with chronologically constrained sequences, such as marine/lake sediments, polar/ alpine ice cores, and peatlands. ${ }^{17}$ China, with 1.36 billion people in East Asia, has been regarded as the world's largest EC contributor, accounting for approximately a fifth of global emissions. ${ }^{8,20}$ Consequently, over the latest decade there have been increasing investigations on EC historical records and their responses to anthropogenic activities in China. However, the available studies focused mainly on background areas on the Tibetan Plateau (e.g., Lake Nam Co and Lake Qinghai) ${ }^{11,21}$ and inland peatlands/wetlands/lakes in eastern China, ${ }^{10,16,22-27}$ with the former EC mainly from long-range transport and the latter EC primarily from local emission. Thus, for an all-sided understanding of historical influences of anthropogenic activities in China, EC needs to be studied at a national scale, especially in areas dominated by strong EC emissions.

There are several marginal seas located to the east off mainland China. ${ }^{28}$ Driven by strong northerly/northwesterly winter and spring prevailing East Asian monsoon and large amounts of riverine outflow, in particular from two large rivers, the Yellow and Yangtze Rivers, which drain highly industrialized Chinese megacities in their middle and lower reaches, the eastern China marginal seas are undoubtedly important sinks of EC from mainland China. ${ }^{8,29-31}$ Additionally, under strong influence of regional ocean current systems, several mud areas developed in these marginal seas, ${ }^{32,33}$ in which EC can be preferentially deposited and subsequently sequestered in these regions. ${ }^{8}$ Therefore, the extensively distributed mud areas from eastern China marginal seas (Figure 1) are ideal places to 
extract sediment cores for reconstructing the nationwide historical anthropogenic activities primarily from China.

In this study, we present the spatiotemporal trends of EC and char/soot ratios in five sediment cores from scattered mud areas in eastern China marginal seas, spatially spanning from inshore coastal mud areas $(\sim 50 \mathrm{~km})$ in the East China Sea to offshore remote central mud areas $(\sim 300 \mathrm{~km})$ in the Yellow Sea. The major objectives were (1) to elucidate coupled relationships between the temporal trends of EC depositional fluxes and nationwide historical anthropogenic activities in China over the past $\sim 150$ years and (2) on the basis of differences in formation mechanisms (e.g., temperatures) and physicochemical properties (e.g., particle sizes and therefore transportability) between char and soot, to explore the powerful indicators of the spatiotemporal trends of char/soot ratios. This study, as far as we know, is the first to evaluate both input history and transport patterns of pyrogenic EC on such a large spatial scale as the eastern China marginal seas (covering four sea regions), which are hot topics of focus by some global community programs. ${ }^{34,35}$ Furthermore, our results will also provide a critical database for refining the significance of continental shelves in global EC cycling, with existing estimates demonstrating that $>90 \%$ of global EC is buried on continental shelves although they comprise only $10 \%$ of global ocean area. 8,36

\section{MATERIALS AND METHODS}

2.1. Sediment Core Collection. Five sediment cores, including one from Bohai Sea (BHS), one from northern Yellow Sea (NYS), one from southern Yellow Sea (SYS), and two from East China Sea (ECS1 and ECS2), were collected by gravity corers deployed from research vessels Dong Fang Hong 2 and Ke Yan 59 from 2003 to 2011 (Figure 1; Table S1). All cores were retrieved from mud areas of each sea region. The core samples were cut into sections of 1 or $2 \mathrm{~cm}$ down the core length with a stainless steel cutter, either in situ on board the research vessels or in the laboratory. The sediment slices were packed in aluminum foil (combusted at $450{ }^{\circ} \mathrm{C}$ for $4 \mathrm{~h}$ before use). They were then stored at $-20{ }^{\circ} \mathrm{C}$ until further analysis.

2.2. Analyses of Sediment Grain Size and Sediment Dating. Detailed analytical procedures for sediment grain size and sediment dating are described in sections S1 and S2, respectively. Notably, only four cores, BHS, NYS, ECS1, and ECS2, were radionuclide ${ }^{210} \mathrm{~Pb}$-dated (Table S2). The sedimentation rate for core SYS was deduced from prior studies, ${ }^{37,38}$ and an approximate value of $0.20 \mathrm{~cm} \cdot \mathrm{yr}^{-1}$ was utilized as a reference.

2.3. Quantification of Sedimentary Elemental Carbon, Char, and Soot. Several EC quantification methods have been developed, ${ }^{2}$ with determined EC concentrations of identified samples varying by up to a factor of 500 between methods. ${ }^{39}$ This study adopted the wet-chemical treatment integrated with thermal optical reflectance (TOR) method to quantify EC. The TOR approach has been used for reconstructing EC pollution history, and it has powerful potential to effectively differentiate between char and soot. ${ }^{10,11,14}$ Prior to chemical treatment, the sediment samples were thawed, freeze-dried, and homogenized ( $<80$ mesh). Then they were digested with $\mathrm{HCl} / \mathrm{HF}$ acids to eliminate inorganic carbonates, metals, metal oxides, and silicates. The remaining residue was filtered through 47-mm-diameter circular quartz fiber filters that had been prebaked at $450{ }^{\circ} \mathrm{C}$ for $4 \mathrm{~h}$. The carbonate-free filter samples were air-dried.
Subsequently, they were analyzed for EC on a thermal/optical carbon analyzer (model 2001) manufactured by Desert Research Institute. The interagency monitoring of protected visual environment (IMPROVE) protocol was adopted. A circular punch of $0.544 \mathrm{~cm}^{2}$ was sent into an oven for carbon analysis. To begin, the oven was heated in $100 \% \mathrm{He}$ condition, yielding four organic carbon fractions in four different temperature stages. Afterward, the analysis condition was switched to $\mathrm{O}_{2} / \mathrm{He}$ mixture (2\%/98\%). Correspondingly, three EC fractions (defined as EC1, EC2, and EC3) were released in three temperature stages $\left(580,740\right.$, and $\left.840{ }^{\circ} \mathrm{C}\right)$. Pyrolysis of organic carbon (POC) took place in $100 \% \mathrm{He}$ atmosphere, as reflected from the decreased reflectance signal in the laser. POC similar to the original EC fraction was oxidized in the second $\mathrm{O}_{2} / \mathrm{He}$ stage. According to the IMPROVE protocol, EC was calculated according to the formula EC1 + EC2 + EC3 - POC. Furthermore, Han et al. ${ }^{40}$ examined the thermograms of seven char and three soot reference materials, following the same protocol as in the present study. They found that char evolved almost exclusively in EC1 step and soot in EC2 + EC3 steps. Char was therefore calculated as EC1 - POC and soot as EC2 + EC3. More elaborate analytical procedures regarding the sedimentary EC, char, and soot quantification are available in our recent studies. ${ }^{8,41}$

2.4. Quality Assurance and Quality Control. A primary factor influencing the accuracy of EC concentration determination is whether the acid-treated sediment residue loaded on filters has an even distribution. ${ }^{8,42}$ For confirmation, we randomly chose $10 \%$ of total filters $(n=21)$ and drilled two punches from different locations in each filter. The relative standard deviation (RSD) of EC concentrations measured from the two punches was $0-10 \%$ and averaged $<4 \%$. This demonstrated that the sediment residues distributed evenly on the filters. In addition, blanks and replicates, as well as National Institute of Standards and Technology standard reference material (NIST SRM-1941b, marine sediments collected in Baltimore Harbor, USA), were also quantified. The blanks ( $n=$ 21) showed nondetectable EC concentrations. The RSD of 21 pairs of replicates was $0-12 \%$ and averaged $<7 \%$. The EC content in NIST SRM-1941b was $10.84 \pm 1.92 \mathrm{mg} \cdot \mathrm{g}^{-1}(n=$ 21 ; all weights are dry weight), which was well consistent with values in recent studies (Table S3). ${ }^{8,21,41,43}$ These quality assurance and quality control measures indicate that the EC methodology used was credible and reproducible.

\section{RESULTS AND DISCUSSION}

3.1. Depositional Settings. The five sediment cores had similar relative proportions of sediment composition, sorting in a decreasing order of silt $>$ clay $>$ sand (Figure S1, Table S4). The fine clay and silt fractions $(<63 \mu \mathrm{m})$ constituted more than $95 \%$ of sediments, and the coarse sand fraction $(>63 \mu \mathrm{m})$ accounted for less than $5 \%$. The vertical variation of sediment composition was small in all cores, with the exceptions of cores BHS and SYS, suggesting relatively stable dynamic depositional settings in these sampling regimes. Following the stable sedimentary environments, sediments are well-preserved at these sampling sites, and thus the collected sediment cores are well-suited for EC studies. For cores BHS and SYS, however, there were some small fluctuations in sediment composition (Figure S1).

Cores ECS1 and ECS2 in the Min-Zhe coastal mud area (MZCMA, Figure 1) had the highest sedimentation rates (0.98 and $1.05 \mathrm{~cm} \cdot \mathrm{yr}^{-1}$, respectively; Figure S2 and Table S1). The 
Table 1. Depositional Fluxes of Elemental Carbon in Five Sediment Cores from the Eastern China Marginal Seas and Comparisons with Recent Studies Using Similar Thermal Optical Methods

\begin{tabular}{|c|c|c|c|c|}
\hline study area (core label) & core location description & year span & $\begin{array}{l}\text { EC depositional flux range (average), } \\
\qquad \mathrm{g} \cdot \mathrm{m}^{-2} \cdot \mathrm{yr}^{-1}\end{array}$ & ref \\
\hline Bohai Sea (BHS) & central mud area, strongly affected by the Yellow River & $1883-2006$ & $3.79-11.16(5.51 \pm 1.55)$ & this study \\
\hline $\begin{array}{l}\text { Northern Yellow Sea } \\
\text { (NYS) }\end{array}$ & central mud area, atmospheric deposition dominated & $1861-2011$ & $0.97-2.58(1.40 \pm 0.43)$ & this study \\
\hline Southern Yellow Sea (SYS) & central mud area, atmospheric deposition dominated & $1861-2011$ & $0.97-2.25(1.47 \pm 0.32)$ & this study \\
\hline East China Sea (ECS1) & coastal mud area, strongly affected by the Yangtze River & $1870-2003$ & $8.14-25.10(12.58 \pm 3.78)$ & this study \\
\hline East China Sea (ECS2) & coastal mud area, strongly affected by the Yangtze River & $1869-2009$ & $4.00-27.37(9.95 \pm 5.65)$ & this study \\
\hline Lake Taihu & $\begin{array}{l}\text { an inland lake in highly industrialized region, eastern } \\
\text { China }\end{array}$ & $1850-2003$ & $1.15-6.89(3.29)$ & 10 \\
\hline Lake Chaohu & $\begin{array}{l}\text { inland lake in moderately industrialized region, eastern } \\
\text { China }\end{array}$ & $1860-2006$ & $1.70-5.67(3.16)$ & 10 \\
\hline Lake Nam Co (NCM09) & background area, atmospheric deposition dominated & $1857-2009$ & $0.12-0.44(0.26)$ & 21 \\
\hline Lake Qinghai (QH03-14) & background area, atmospheric deposition dominated & $1780-2003$ & $0.27-0.98(0.39)$ & 11 \\
\hline Lake Qinghai (QH11-1) & background area, atmospheric deposition dominated & $1780-2011$ & $0.22-0.36(0.27)$ & 11 \\
\hline Bohai Bay (S4, S5, and S8) & coastal area adjacent to highly industrialized mega-city & $1895-2011$ & $0.09-8.23(1.78)$ & 16 \\
\hline
\end{tabular}
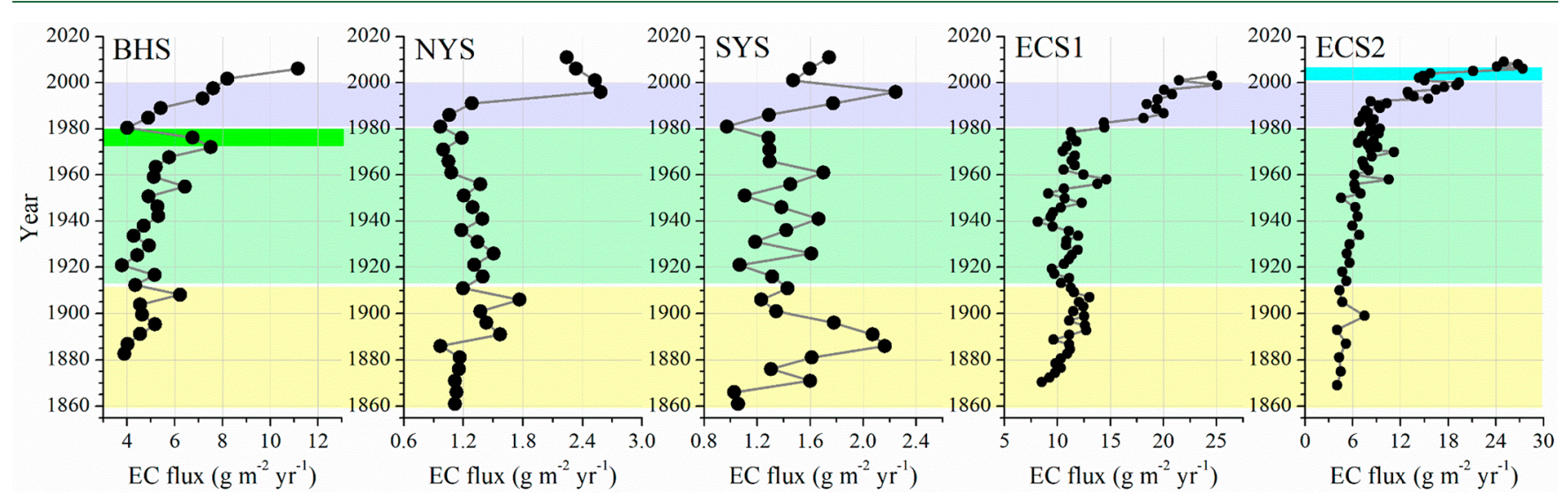

Figure 2. Temporal trends of EC depositional fluxes in five sediment cores from the eastern China marginal seas.

sedimentation rate for core BHS $\left(0.47 \mathrm{~cm} \cdot \mathrm{yr}^{-1}\right)$ was only half that of cores ECS1 and ECS2, but it was still 2 times higher than those of cores NYS and SYS (both were $0.20 \mathrm{~cm} \cdot \mathrm{yr}^{-1}$ ), which were collected in central mud areas of northern and southern Yellow Seas. The relatively higher sedimentation rates for cores ECS1, ECS2, and BHS were largely attributable to large amounts of sediment inputs from Yangtze and Yellow Rivers, respectively (Figure 1). In terms of sediment loads, Yangtze and Yellow Rivers are the fourth- and second-largest rivers in the world, respectively, and they each have been shown to impact significantly the sedimentary circumstances of MZCMA of East China Sea and the central mud area of Bohai Sea. 44,45

3.2. Elemental Carbon Concentrations and Depositional Fluxes. Cores BHS, NYS, SYS, ECS1, and ECS2 had EC concentration ranges of $0.59-1.36,0.56-1.32,0.51-1.18$, 1.03-2.37, and $0.59-1.48 \mathrm{mg} \cdot \mathrm{g}^{-1}$, with averages of $0.93 \pm$ $0.15,0.78 \pm 0.19,0.77 \pm 0.17,1.46 \pm 0.23$, and $0.91 \pm 0.22$ $\mathrm{mg} \cdot \mathrm{g}^{-1}$, respectively (Table S4). Considering that EC in sediments may be diluted or concentrated because of inputs of mineral and organic matter, ${ }^{16,36}$ the EC depositional fluxes were more favorable than EC concentrations for reflecting the real EC inputs. The ranges of EC depositional flux for cores BHS, NYS, SYS, ECS1, and ECS2 were 3.79-11.16, 0.97$2.58,0.97-2.25,8.14-25.10$, and $4.00-27.37 \mathrm{~g} \cdot \mathrm{m}^{-2} \cdot \mathrm{yr}^{-1}$, respectively, and their corresponding averages were $5.51 \pm$ $1.55,1.40 \pm 0.43,1.47 \pm 0.32,12.58 \pm 3.78$, and $9.95 \pm 5.65$ $\mathrm{g} \cdot \mathrm{m}^{-2} \cdot \mathrm{yr}^{-1}$ (Table S4). The relative magnitude of average EC depositional fluxes for these cores was consistent with their average sedimentation rates, with higher values for cores ECS1, ECS2, and BHS and relatively lower values for cores NYS and SYS, suggesting strong impact of large riverine discharges on anthropogenic EC from land to coastal ocean ecosystems.

Compared with recent investigations in other regions using a similar thermal optical method (Table 1), our average EC depositional fluxes from eastern China marginal seas were of the same magnitude as those observed in lakes and salt marshes from moderately to highly industrialized areas of eastern China $\left(3.16-3.29 \mathrm{~g} \cdot \mathrm{m}^{-2} \cdot \mathrm{yr}^{-1}\right)$ and the North China Plain $\left(1.78 \mathrm{~g} \cdot \mathrm{m}^{-2} \cdot \mathrm{yr}^{-1}\right) \cdot{ }^{10,16}$ However, they were nearly 50 times higher than values detected in background areas, such as Lake Nam Co $\left(0.26 \mathrm{~g} \cdot \mathrm{m}^{-2} \cdot \mathrm{yr}^{-1}\right)$ and Lake Qinghai (0.27-0.39 $\left.\mathrm{g} \cdot \mathrm{m}^{-2} \cdot \mathrm{yr}^{-1}\right)$ on the Tibetan Plateau. ${ }^{11,21}$ The significantly lower levels of EC depositional fluxes on the Tibetan Plateau were mainly attributed to its relatively pristine environments, characterized by extremely sparse populations and limited local industries, and long-range atmospheric transport and subsequent deposition (including dry and wet) dominated their EC inputs. ${ }^{11,21}$

3.3. Temporal Trends of Elemental Carbon Depositional Fluxes: Tracking Historical Anthropogenic Activities in China. The temporal trends of EC depositional fluxes for five sediment cores from eastern China marginal seas are illustrated in Figure 2, and they closely tracked historical anthropogenic activities in China over the past $\sim 150$ years. 
The timeline could be broadly divided into the following four time periods.

Early 1860s to Early 1900s. The EC depositional fluxes in all cores showed increasing trends beginning in the 1860s and reached peak values between the 1890s and early 1900s, with peak fluxes $\sim 1.5-2$ times higher than that in 1860s (Table S4). The period of EC peak fluxes coincided well with the timing of the Westernization Movement (1861-1894). The Westernization Movement after the two opium wars (First Opium War, 1840-1842; Second Opium War, 1856-1860) pressured China to open for trade and start industrializing, ${ }^{28,46}$ which may have been responsible for the first EC increases and the subsequent peak EC depositional fluxes in these cores from the marginal seas.

Late 1900s to Late 1970s. This long time period encompassed more diverse historical trends in EC depositional fluxes among the sediment cores. For core BHS, the EC depositional fluxes increased slightly from $\sim 5.0 \mathrm{~g} \cdot \mathrm{m}^{-2} \cdot \mathrm{yr}^{-1}$ in the late $1900 \mathrm{~s}$ to $\sim 7.0 \mathrm{~g} \cdot \mathrm{m}^{-2} \cdot \mathrm{yr}^{-1}$ in the early $1970 \mathrm{~s}$, but thereafter they abruptly decreased until reaching $4.0 \mathrm{~g} \cdot \mathrm{m}^{-2} \cdot \mathrm{yr}^{-1}$ in the late 1970s, approaching the lowest EC depositional flux $\left(3.8 \mathrm{~g} \cdot \mathrm{m}^{-2} \cdot \mathrm{yr}^{-1}\right)$ throughout this whole century-long sedimentary record. The abrupt decline in EC depositional fluxes largely resulted from the diversion of the mouth of Yellow River. $^{47}$ A previous study ${ }^{48}$ using multiple geochemical indexes, such as $\mathrm{CaO} / \mathrm{TiO}_{2}$ and chemical index of alteration (CIA), has shown that sediments in sampling region of core BHS were mainly derived from the mixture of clay/silt Yellow River sediments and fine/middle-fine sand Luan River sediments (Figure 1). The diversion of the terminal course of Yellow River in 1976 from Diaokou (DK, gray dotted line) in outer Bohai Bay to Qingshuigou (QSG, gray solid line) in Laizhou Bay (Figure 1) transported most of the Yellow River sediments from central Bohai Sea to Laizhou Bay in southern Bohai Sea. This shift resulted in a decreased influence from the Yellow River but conversely increased influence from the Luan River on sediment compositions of core BHS, as clearly evidenced by elevated proportions of sand component (Figure S1). Compared with the coarser sand component, (sub)micrometer-sized EC particles were more prone to adsorption by fine clay/silt components. ${ }^{8}$ The abruptly elevated sand fraction following the shift of the Yellow River mouth was not conducive to enrichment of fine EC particles, and thus EC depositional fluxes decreased in response.

The EC depositional fluxes for core NYS from the late 1900s to the late 1970 s were within a narrow range of $1.1-1.4 \mathrm{~g} \cdot \mathrm{m}^{-2}$. $\mathrm{yr}^{-1}$ (average $1.3 \pm 0.2 \mathrm{~g} \cdot \mathrm{m}^{-2} \cdot \mathrm{yr}^{-1}$ ), while core SYS demonstrated somewhat larger fluctuations, which corresponded well with the changes in sediment composition (Figure S1). For cores ECS1 and ECS2, the EC depositional fluxes also showed small variations as that of core NYS, ranging from $\sim 9.0$ to $\sim 11.0 \mathrm{~g} \cdot \mathrm{m}^{-2} \cdot \mathrm{yr}^{-1}$ and $\sim 6.0$ to $\sim 8.0 \mathrm{~g} \cdot \mathrm{m}^{-2} \cdot \mathrm{yr}^{-1}$, respectively. Of particular note, however, was that several anomalously high EC depositional flux values were concurrently observed in these two near-shore coastal mud sediment cores, i.e., $13.8-14.6 \mathrm{~g} \cdot \mathrm{m}^{-2} \cdot \mathrm{yr}^{-1}$ for core ECS1 in $\sim 1956-1958,10.5 \mathrm{~g} \cdot \mathrm{m}^{-2} \cdot \mathrm{yr}^{-1}$ for core ECS2 in $\sim 1958$, and $11.2 \mathrm{~g} \cdot \mathrm{m}^{-2} \cdot \mathrm{yr}^{-1}$ for core ECS2 in $\sim 1970$. These time periods corresponded to the timing of several medium-to-large flood events in the Yangtze River drainage basin (1954 and 1969). ${ }^{44}$ The extreme stripping and accompanying leaching induced by flood transported more anthropogenic EC, previously stored in soil and water systems of the Yangtze River drainage basin, into the Yangtze River estuary. Subsequently, this was delivered to regions of cores ECS1 and ECS2 by the southward ZhejiangFujian coastal current (ZFCC) (Figure 1).

Early 1980s to Late 1990s. With implementation of the Reform and Open policy by the Chinese government in 1978, China entered a rapid industrialization and urbanization period, and the requirement for energy from fossil fuels (coal and petroleum/oil) increased drastically (Figure S3). Consequently, the early 1980s witnessed increasing trends of EC depositional fluxes in all sediment cores. It was noticeable, however, that such increasing trends were more pronounced in the early 1990s, which was associated with widespread occurrence of small-scale coke production ${ }^{49}$ and therefore increased EC emission from the industrial sector. According to the latest compiled EC emission inventory, ${ }^{50}$ the annual EC emission from the industrial sector in China was estimated to increase from $324 \mathrm{Gg}$ in 1990 to $758 \mathrm{Gg}$ in 1996 (Figure S4), for an average annual increase of $15.2 \%$.

After the mid-1990s, the EC depositional fluxes in cores NYS and SYS both began to decrease. This was mainly attributed to the gradual phase-out of beehive coke ovens following implementation of the Coal Law in 1996 and the substitution of domestic coal stoves with natural gas/liquid petroleum gas stoves, ${ }^{50}$ which decreased industrial and residential EC emissions, respectively. Annual EC emissions in China from industrial and residential sectors decreased from 758 and $1200 \mathrm{Gg}$ in 1996 to 521 and $911 \mathrm{Gg}$ in 2000, respectively (Figure S4). ${ }^{50}$ In contrast to those of cores NYS and SYS, which were collected in remote central mud areas and less affected by large local riverine inputs, EC depositional fluxes in cores ECS1 and ECS2, located in inshore coastal mud areas, did not decrease in the mid-1990s but continued to increase significantly until they reached their peak values in the late $1990 \mathrm{~s}$, i.e., $25.1 \mathrm{~g} \cdot \mathrm{m}^{-2} \cdot \mathrm{yr}^{-1}$ for ECS1 in $\sim 1999$ and $19.1-$ $19.4 \mathrm{~g} \cdot \mathrm{m}^{-2} \cdot \mathrm{yr}^{-1}$ for ECS2 in $\sim 1999-2000$ (Table S4). The continuous increase of EC depositional fluxes for cores ECS1 and ECS2 during this period again reflected strong influence from the severe flood event that occurred in middle and lower reaches of the Yangtze River drainage basin in $1998 .{ }^{44}$ Based on the same sediment core ECS1, Guo et al. ${ }^{51}$ and Hao et al. ${ }^{52}$ also found strong associations of peaks of pyrogenic polycyclic aromatic hydrocarbons (PAHs) and heavy metal lead $(\mathrm{Pb})$, respectively, in the late 1990s with the 1998 catastrophic flood event.

Early 2000s to Sampling Date. Due to the low time resolution and limited number of sediment slices from the early 2000s until the sampling date for cores BHS, NYS, SYS, and ECS1, only core ECS2 is discussed for this period.

After the peak value for core ECS2 in the late 1990s caused by the 1998 flood event, the EC depositional fluxes increased once more in the early $2000 \mathrm{~s}$, jumping from $15.0 \mathrm{~g} \cdot \mathrm{m}^{-2} \cdot \mathrm{yr}^{-1}$ in $\sim 2001$ to $27.4 \mathrm{~g} \cdot \mathrm{m}^{-2} \cdot \mathrm{yr}^{-1}$ in $\sim 2006$, with mean annual increase of up to $12.8 \%$. Thereafter, the EC depositional fluxes maintained relatively constant values $\left(24.2-27.4 \mathrm{~g} \cdot \mathrm{m}^{-2} \cdot \mathrm{yr}^{-1}\right)$. During the first several years of the 21 st century, another phase of industrialization and urbanization proceeded, and small- to medium-sized cities and towns with total populations $<1$ million became urban centers. ${ }^{53} \mathrm{~A}$ direct consequence was the corresponding increases in domestic coal consumption and coke production, which increased residential and industrial EC emissions. ${ }^{50}$ Additionally, the rapid growth in the number of vehicles owned (Figure S3), accompanying urbanization, was another important source of increased EC emission and 

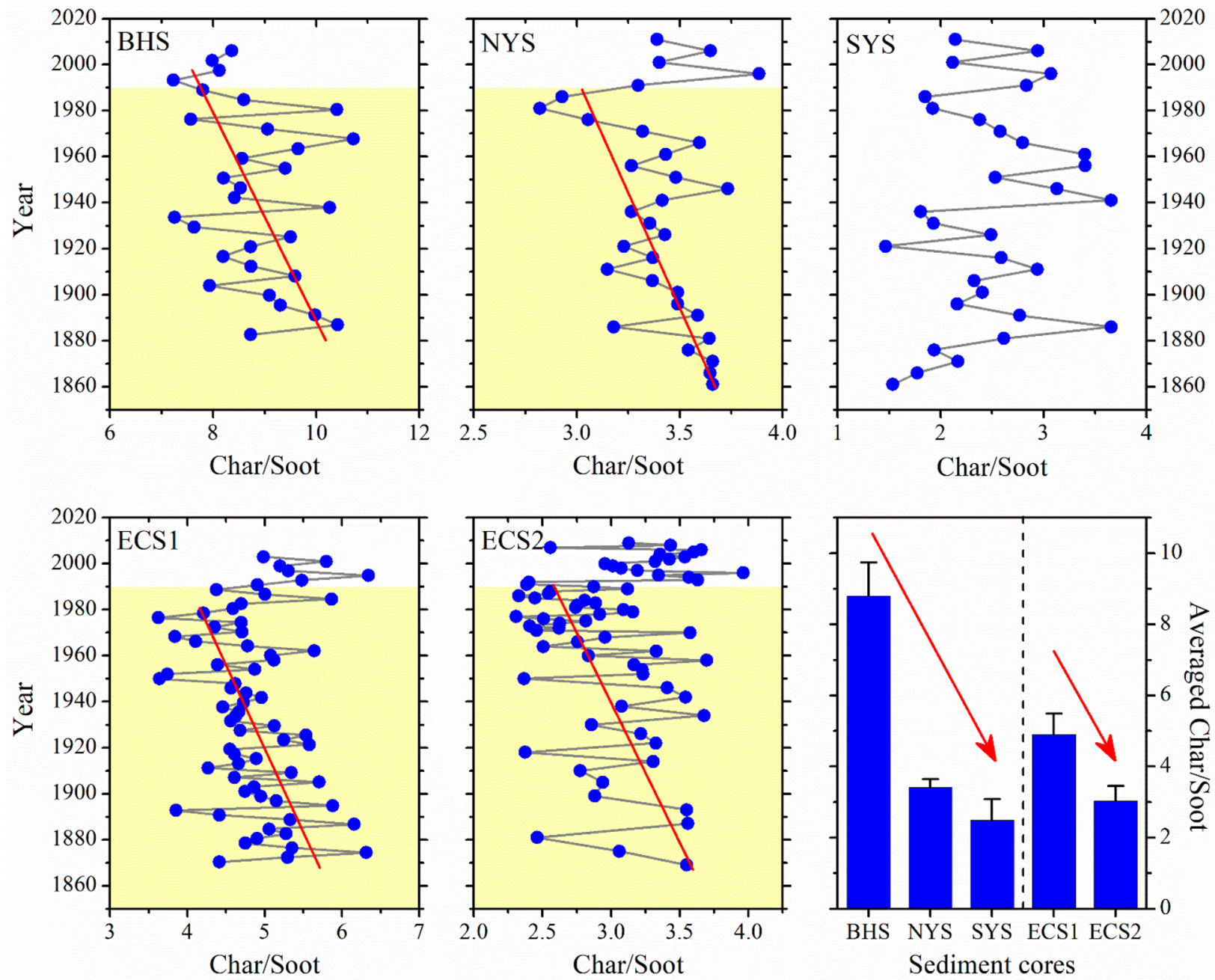

Figure 3. Spatiotemporal trends of char/soot ratios in five sediment cores from eastern China marginal seas. Red trend lines within the yellow shaded areas were limited from the bottom to the subsurface layers, that is, before $\sim 1990$ s.

subsequent EC transport and burial. The estimated EC emissions from residential, industrial, and transportation departments increased from 947, 501, and $107 \mathrm{Gg}$ in 2001 to 1061,578 , and $198 \mathrm{Gg}$, respectively, in 2006 (Figure S4). ${ }^{50}$

The overall historical EC trends observed in sediments from eastern China marginal seas showed some similarities to those extracted from other environmental archives in China, such as inland lake sediments ${ }^{10}$ and wetlands/peatlands, ${ }^{16,22-27}$ especially the pronounced increasing trend since the early 1980 s induced by the national political movement of implementing the Reform and Open policy. Coincidentally, almost all available sedimentary studies on PAHs, ${ }^{28,46,47,51,54,55}$ which share similar formation mechanisms and sources with $\mathrm{EC},{ }^{56}$ have also observed remarkable increasing trends at the same time. The nationwide universality of such pronounced increasing trends since the early 1980 s may provide the possibility of using year 1978 as a ruler for roughly estimating the sedimentation rate of an undated sediment core, if analysis indeed showed a pronounced increasing trend for EC and/or PAHs. As a case study, for the undated core SYS, the designation of the starting point of pronounced EC increasing trend at $6-7 \mathrm{~cm}$ as year 1978 resulted in a sedimentation rate of $\sim 0.197 \mathrm{~cm} \cdot \mathrm{yr}^{-1}$ (6.5 $\mathrm{cm}$ divided by 33 years), which is highly consistent with previous measurements in this sea region. ${ }^{37,38}$ This estimation further confirms that the $0.20 \mathrm{~cm}$. $\mathrm{yr}^{-1}$ sedimentation rate we used in this work for core SYS is of high confidence. In addition, the hypothesis could also be wellattested from the other four ${ }^{210} \mathrm{~Pb}$-dated cores.

The temporal trends of EC depositional fluxes in China differed significantly from those examined in European and American countries. ${ }^{15,17,57-59}$ The EC fluxes in those countries increased after the mid-1800s and mostly peaked in the early to middle 1900s, commensurate with the industrial revolution. After the 1960s, they declined because of a combination of increasing usage of clean energy (e.g., hydropower and nuclear power) and implementation of strict particle emission control measures. On the basis of these comparisons, it was anticipated that differences in sedimentary EC profiles among these countries were indicative of different socioeconomic development stages.

In terms of the temporal trends of char and soot depositional fluxes, it was apparent that they both resembled those of EC (Figure S5), but the consistency between char and EC was more pronounced than that between soot and EC, as clearly substantiated by higher significant correlation between them (Figure S6). Given that char constituted a vast majority of the EC component (70-90\% on average) (Table S4), the higher consistency between char and EC was thus not surprising.

3.4. Spatiotemporal Trends of Char/Soot Ratios: Indicators of Changing Energy Structures and Differ- 
ential Transport Patterns. The benefit of the TOR method is that it has been demonstrated to differentiate between two subtypes of EC, char and soot, with different formation mechanisms and physicochemical properties. Therefore, it is expected that the spatiotemporal trends of char/soot ratios (Figure 3) may provide meaningful information on energy structure evolution and differential transport patterns.

Temporally, although the historical trends of both char and soot depositional fluxes resembled those of EC (Figure S5), the char/soot ratios did not remain constant within these cores. Aside from core SYS, the char/soot ratios in the other four cores showed decreasing trends from bottom to subsurface layers (before $\sim 1990$ s) but abrupt increases at uppermost layers (after $\sim 1990$ s). Given that char is the combustion residue primarily produced from low-temperature combustion, whereas soot is the condensation product from high-temperature combustion in flames, ${ }^{10,13}$ such decreasing trends of char/soot ratios during the 20th century indicate a shift in energy structure from low-temperature to hightemperature combustion activities. This phenomenon further reflects the switch from an agricultural economy to an industrial economy in China. Guo et al. ${ }^{46}$ previously examined the historical PAH signatures in the East China Sea and found that there was an apparent increase in the relative proportion of high-molecular-weight 5-6-membered ring PAHs over the past two centuries. The shift of PAH signatures also reflects such switch of economic patterns as extracted in the present study. Unfortunately, the potential reasons for the abrupt increase in char/soot ratios over the latest two decades remain unknown.

Spatially, the average char/soot ratios decreased significantly from core BHS $(8.8 \pm 0.9)$ to cores NYS $(3.4 \pm 0.2)$ and SYS (2.5 \pm 0.6$)$ (Figure 3; Table S4). Similarly, such a decreasing trend was also observed from core ECS1 $(4.9 \pm 0.6)$ to core ECS2 $(3.0 \pm 0.4)$. Considering smaller particle sizes and stronger transportability of soot than char, the lower char/soot ratios in cores NYS and SYS compared with BHS, and in ECS2 compared with ECS1, indicated that EC in the regions of cores NYS, SYS, and ECS2 were mainly derived from longer-distance transport than EC in the regions of cores BHS and ECS1. This conclusion coincided well with the following inference from their geographical locations (Figure 1). Core BHS is adjacent to near-shore areas $(\sim 60 \mathrm{~km})$ and directly receives large riverine inputs (mainly from the Yellow and Luan Rivers). For cores NYS and SYS, however, there are no direct large local riverine inputs, and they are also far from their direct source, the Bohai Sea. Therefore, long-range hydrodynamic transport from remote large rivers (e.g., for core NYS, distances from both Yellow and Yalu Rivers are more than $250 \mathrm{~km}$ ) and potential influence of long-range atmospheric transport may have contributed to EC in regions of cores NYS and SYS. For cores ECS1 and ECS2 in MZCMA, the EC is discharged mainly from the Yangtze River and then transported from north to south (i.e., from core ECS1 to core ECS2) due to combined influences of the driving force of Zhejiang-Fujian coastal current (ZFCC) and obstruction by strong Taiwan warm current (TWWC) (Figure 1).

This assessment regarding char/soot ratios indicates that it is essential to differentiate between char and soot in future ECassociated studies, which may significantly strengthen our understanding of EC environmental geochemistry, such as present powerful indicators of changing energy structures and differential transport patterns. In addition, the two subtypes of
EC also exert different influences on the fate of environmental pollutants (e.g., persistent organic pollutants, heavy metals, etc.). For instance, Han et al. ${ }^{60}$ recently found a stronger association of PAHs with soot than with char in sediments and soils.

\section{ASSOCIATED CONTENT}

\section{S Supporting Information}

The Supporting Information is available free of charge on the ACS Publications website at DOI: 10.1021/acs.est.8b00033.

Four tables listing detailed descriptions and measured geochemical parameters of five sediment cores and comparing EC concentrations in NIST SRM-1941b; Two texts presenting detailed analytical procedures for sediment grain size and sediment dating; Six figures showing spatiotemporal trends of sediment grain size,

${ }^{210} \mathrm{~Pb}$ dating of four sediment cores, statistical data on socioeconomic development indexes in China from 1952 to 2013, EC emission inventory in China from 1976 to 2014, and temporal trends and correlations between char, soot, and EC depositional fluxes (PDF)

\section{AUTHOR INFORMATION}

\section{Corresponding Authors}

*Phone/fax: +86-21-65983869; E-mail: yjchentj@tongji.edu. cn (Y.C.).

*Phone/fax: +86-851-85895239; E-mail: lintian@vip.gyig.ac. cn (T.L.).

ORCID $\odot$

Yin Fang: 0000-0002-8977-5552

Yingjun Chen: 0000-0002-4784-8282

Tian Lin: 0000-0001-9813-7782

Chongguo Tian: 0000-0001-6058-9353

Jun Li: 0000-0002-3637-1642

Gan Zhang: 0000-0002-9010-8140

Notes

The authors declare no competing financial interest.

\section{ACKNOWLEDGMENTS}

This work was financially supported by National Natural Scientific Foundation of China (41703087, 91744203, 41761134083, 41473091, 41430646, and 41722603), Key Laboratory of Coastal Environmental Processes and Ecological Remediation of YICCAS (2016KFJJ04), State Key Laboratory of Organic Geochemistry of GIGCAS (SKLOG-201620), Key Laboratory of Yangtze River Water Environment of Ministry of Education in Tongji University (YRWEF201802), Basic Scientific Fund for National Public Research Institutes of China (2017S01), and Fundamental Research Funds for the Central Universities. We thank the crew of R/V Dong Fang Hong 2 of Ocean University of China and R/V Ke Yan 59 for collecting the sediment core samples.

\section{REFERENCES}

(1) Santin, C.; Doerr, S. H.; Kane, E. S.; Masiello, C. A.; Ohlson, M.; de la Rosa, J. M.; Preston, C. M.; Dittmar, T. Towards a global assessment of pyrogenic carbon from vegetation fires. Global Change Biol. 2016, 22 (1), 76-91.

(2) Hammes, K.; Schmidt, M. W. I.; Smernik, R. J.; Currie, L. A.; Ball, W. P.; Nguyen, T. H.; Louchouarn, P.; Houel, S.; Gustafsson, Ö.; Elmquist, M.; Cornelissen, G.; Skjemstad, J. O.; Masiello, C. A.; Song, J.; Peng, P. a.; Mitra, S.; Dunn, J. C.; Hatcher, P. G.; Hockaday, W. C.; 
Smith, D. M.; Hartkopf-Fröder, C.; Böhmer, A.; Lüer, B.; Huebert, B. J.; Amelung, W.; Brodowski, S.; Huang, L.; Zhang, W.; Gschwend, P. M.; Flores-Cervantes, D. X.; Largeau, C.; Rouzaud, J.-N.; Rumpel, C.; Guggenberger, G.; Kaiser, K.; Rodionov, A.; Gonzalez-Vila, F. J.; Gonzalez-Perez, J. A.; de la Rosa, J. M.; Manning, D. A. C.; LópezCapél, E.; Ding, L. Comparison of quantification methods to measure fire-derived (black/elemental) carbon in soils and sediments using reference materials from soil, water, sediment and the atmosphere. Global Biogeochem. Cycles 2007, 21 (3), No. GB3016.

(3) Wiedemeier, D. B.; Hilf, M. D.; Smittenberg, R. H.; Haberle, S. G.; Schmidt, M. W. I. Improved assessment of pyrogenic carbon quantity and quality in environmental samples by high-performance liquid chromatography. J. Chromatogr. A 2013, 1304 (0), 246-250.

(4) Santin, C.; Doerr, S. H.; Preston, C. M.; Gonzalez-Rodriguez, G. Pyrogenic organic matter production from wildfires: a missing sink in the global carbon cycle. Global Change Biol. 2015, 21 (4), 16211633.

(5) Ramanathan, V.; Carmichael, G. Global and regional climate changes due to black carbon. Nat. Geosci. 2008, 1 (4), 221-227.

(6) Anenberg, S. C.; Schwartz, J.; Shindell, D.; Amann, M.; Faluvegi, G.; Klimont, Z.; Janssens-Maenhout, G.; Pozzoli, L.; Van Dingenen, R.; Vignati, E.; Emberson, L.; Muller, N. Z.; West, J. J.; Williams, M.; Demkine, V.; Hicks, W. K.; Kuylenstierna, J.; Raes, F.; Ramanathan, V. Global Air Quality and Health Co-benefits of Mitigating NearTerm Climate Change through Methane and Black Carbon Emission Controls. Environ. Health Perspect. 2012, 120 (6), 831-839.

(7) Wang, R.; Tao, S.; Balkanski, Y.; Ciais, P.; Boucher, O.; Liu, J.; Piao, S.; Shen, H.; Vuolo, M. R.; Valari, M.; Chen, H.; Chen, Y.; Cozic, A.; Huang, Y.; Li, B.; Li, W.; Shen, G.; Wang, B.; Zhang, Y. Exposure to ambient black carbon derived from a unique inventory and high-resolution model. Proc. Natl. Acad. Sci. U. S. A. 2014, 111 (7), 2459-2463.

(8) Fang, Y.; Chen, Y.; Tian, C.; Lin, T.; Hu, L.; Huang, G.; Tang, J.; $\mathrm{Li}$, J.; Zhang, G. Flux and budget of BC in the continental shelf seas adjacent to Chinese high $\mathrm{BC}$ emission source regions. Global Biogeochem. Cycles 2015, 29 (7), 957-972.

(9) Masiello, C. A. New directions in black carbon organic geochemistry. Mar. Chem. 2004, 92 (1-4), 201-213.

(10) Han, Y. M.; Cao, J. J.; Yan, B. Z.; Kenna, T. C.; Jin, Z. D.; Cheng, Y.; Chow, J. C.; An, Z. S. Comparison of Elemental Carbon in Lake Sediments Measured by Three Different Methods and 150-Year Pollution History in Eastern China. Environ. Sci. Technol. 2011, 45 (12), 5287-5293.

(11) Han, Y. M.; Wei, C.; Bandowe, B. A. M.; Wilcke, W.; Cao, J. J.; Xu, B. Q.; Gao, S. P.; Tie, X. X.; Li, G. H.; Jin, Z. D.; An, Z. S. Elemental Carbon and Polycyclic Aromatic Compounds in a 150 -Year Sediment Core from Lake Qinghai, Tibetan Plateau, China: Influence of Regional and Local Sources and Transport Pathways. Environ. Sci. Technol. 2015, 49 (7), 4176-4183.

(12) Schmidt, M. W. I.; Noack, A. G. Black carbon in soils and sediments: Analysis, distribution, implications, and current challenges. Global Biogeochem. Cycles 2000, 14 (3), 777-793.

(13) Elmquist, M.; Cornelissen, G.; Kukulska, Z.; Gustafsson, Ö. Distinct oxidative stabilities of char versus soot black carbon: Implications for quantification and environmental recalcitrance. Global Biogeochem. Cycles 2006, 20 (2), No. GB2009.

(14) Han, Y.; Marlon, J.; Cao, J.; Jin, Z.; An, Z. Holocene linkages between char, soot, biomass burning and climate from Lake Daihai, China. Global Biogeochem. Cycles 2012, 26 (4), No. GB4017.

(15) Elmquist, M.; Zencak, Z.; Gustafsson, Ö. A 700 Year Sediment Record of Black Carbon and Polycyclic Aromatic Hydrocarbons near the EMEP Air Monitoring Station in Aspvreten, Sweden. Environ. Sci. Technol. 2007, 41 (20), 6926-6932.

(16) Xu, W.; Wang, F.; Li, J.; Tian, L.; Jiang, X.; Yang, J.; Chen, B. Historical variation in black carbon deposition and sources to Northern China sediments. Chemosphere 2017, 172, 242-248.

(17) Ruppel, M. M.; Gustafsson, O.; Rose, N. L.; Pesonen, A.; Yang, H.; Weckstrom, J.; Palonen, V.; Oinonen, M. J.; Korhola, A. Spatial and Temporal Patterns in Black Carbon Deposition to Dated
Fennoscandian Arctic Lake Sediments from 1830 to 2010. Environ. Sci. Technol. 2015, 49 (24), 13954-13963.

(18) Xu, B.; Cao, J.; Hansen, J.; Yao, T.; Joswia, D. R.; Wang, N.; Wu, G.; Wang, M.; Zhao, H.; Yang, W.; Liu, X.; He, J. Black soot and the survival of Tibetan glaciers. Proc. Natl. Acad. Sci. U. S. A. 2009, 106 (52), 22114-22118.

(19) Louchouarn, P.; Chillrud, S. N.; Houel, S.; Yan, B.; Chaky, D.; Rumpel, C.; Largeau, C.; Bardoux, G.; Walsh, D.; Bopp, R. F. Elemental and molecular evidence of soot-and char-derived black carbon inputs to New York City's atmosphere during the 20th century. Environ. Sci. Technol. 2007, 41 (1), 82-87.

(20) Bond, T. C.; Streets, D. G.; Yarber, K. F.; Nelson, S. M.; Woo, J. H.; Klimont, Z. A technology-based global inventory of black and organic carbon emissions from combustion. J. Geophys. Res. 2004, 109, No. D14203.

(21) Cong, Z.; Kang, S.; Gao, S.; Zhang, Y.; Li, Q.; Kawamura, K. Historical trends of atmospheric black carbon on Tibetan Plateau as reconstructed from a 150-year lake sediment record. Environ. Sci. Technol. 2013, 47 (6), 2579-2586.

(22) Gao, C.; Lin, Q.; Zhang, S.; He, J.; Lu, X.; Wang, G. Historical trends of atmospheric black carbon on Sanjiang Plain as reconstructed from a 150-year peat record. Sci. Rep. 2014, 4, No. 5723.

(23) He, J.; Gao, C.; Cong, J.; Zhong, J.; Han, D.; Wang, G. Historical pyrogenic sources of black carbon during the last 150 years in the Great Hinggan Mountains, Northeast China. J. Soils Sediments 2017, 18 (3), 708-717.

(24) He, J.; Gao, C.; Lin, Q.; Zhang, S.; Zhao, W.; Lu, X.; Wang, G. Temporal and Spatial Changes in Black Carbon Sedimentary Processes in Wetlands of Songnen Plain, Northeast of China. PLoS One 2015, 10 (10), No. e0140834.

(25) Gao, C.; He, J.; Cong, J.; Zhang, S.; Wang, G. Impact of forest fires generated black carbon deposition fluxes in Great Hinggan Mountains (China). Land Degrad. Dev. 2018, 29, 2073-2081.

(26) Gao, C. Y.; Knorr, K. H.; Yu, Z. G.; He, J. B.; Zhang, S. Q.; Lu, X. G.; Wang, G. P. Black carbon deposition and storage in peat soils of the Changbai Mountain, China. Geoderma 2016, 273, 98-105.

(27) Bao, K.; Shen, J.; Wang, G.; Gao, C. Anthropogenic Black Carbon Emission Increase during the Last 150 Years at Coastal Jiangsu, China. PLoS One 2015, 10 (7), No. e0129680.

(28) Liu, L.-Y.; Wang, J.-Z.; Wei, G.-L.; Guan, Y.-F.; Wong, C. S.; Zeng, E. Y. Sediment Records of Polycyclic Aromatic Hydrocarbons (PAHs) in the Continental Shelf of China: Implications for Evolving Anthropogenic Impacts. Environ. Sci. Technol. 2012, 46 (12), 64976504.

(29) Huang, L.; Zhang, J.; Wu, Y.; Wang, J. Distribution and preservation of black carbon in the East China Sea sediments: Perspectives on carbon cycling at continental margins. Deep Sea Res., Part II 2016, 124, 43-52.

(30) Bao, H.; Niggemann, J.; Luo, L.; Dittmar, T.; Kao, S. Aerosols as a source of dissolved black carbon to the ocean. Nat. Commun. 2017, 8, No. 510.

(31) Fang, Z.; Yang, W.; Chen, M.; Ma, H. Source and fate of dissolved black carbon in the western South China Sea during the Southwest Monsoon prevailing season. J. Geophys. Res.: Biogeosci. 2017, 122 (11), 2817-2830.

(32) Hu, L.; Lin, T.; Shi, X.; Yang, Z.; Wang, H.; Zhang, G.; Guo, Z. The role of shelf mud depositional process and large river inputs on the fate of organochlorine pesticides in sediments of the Yellow and East China seas. Geophys. Res. Lett. 2011, 38 (3), No. L03602.

(33) Li, Y.; Lin, T.; Hu, L.; Feng, J.; Guo, Z. Time trends of polybrominated diphenyl ethers in East China Seas: Response to the booming of PBDE pollution industry in China. Environ. Int. 2016, 92-93, 507-514.

(34) Bianchi, T. S.; Allison, M. A. Large-river delta-front estuaries as natural "recorders' of global environmental change. Proc. Natl. Acad. Sci. U. S. A. 2009, 106 (20), 8085-8092.

(35) Syvitski, J. P. M.; Vörösmarty, C. J.; Kettner, A. J.; Green, P. Impact of Humans on the Flux of Terrestrial Sediment to the Global Coastal Ocean. Science 2005, 308 (5720), 376-380. 
(36) Sánchez-García, L.; Cato, I.; Gustafsson, Ö. The sequestration sink of soot black carbon in the Northern European Shelf sediments. Global Biogeochem. Cycles 2012, 26 (1), No. GB1001.

(37) Alexander, C. R.; DeMaster, D.; Nittrouer, C. Sediment accumulation in a modern epicontinental-shelf setting: the Yellow Sea. Mar. Geol. 1991, 98 (1), 51-72.

(38) Wu, Y.; Zhang, J.; Mi, T.; Li, B. Occurrence of $n$-alkanes and polycyclic aromatic hydrocarbons in the core sediments of the Yellow Sea. Mar. Chem. 2001, 76 (1), 1-15.

(39) Schmidt, M. W. I.; Skjemstad, J. O.; Czimczik, C. I.; Glaser, B.; Prentice, K. M.; Gelinas, Y.; Kuhlbusch, T. A. J. Comparative analysis of black carbon in soils. Global Biogeochem. Cycles 2001, 15 (1), 163167.

(40) Han, Y. M.; Cao, J. J.; Chow, J. C.; Watson, J. G.; An, Z. S.; Jin, Z. D.; Fung, K.; Liu, S. X. Evaluation of the thermal/optical reflectance method for discrimination between char- and soot-EC. Chemosphere 2007, 69 (4), 569-574.

(41) Hu, L.; Shi, X.; Bai, Y.; Fang, Y.; Chen, Y.; Qiao, S.; Liu, S.; Yang, G.; Kornkanitnan, N.; Khokiattiwong, S. Distribution, input pathway and mass inventory of black carbon in sediments of the Gulf of Thailand, SE Asia. Estuarine, Coastal Shelf Sci. 2016, 170, 10-19.

(42) Khan, A. J.; Swami, K.; Ahmed, T.; Bari, A.; Shareef, A.; Husain, L. Determination of elemental carbon in lake sediments using a thermal-optical transmittance (TOT) method. Atmos. Environ. 2009, 43 (38), 5989-5995.

(43) Han, Y. M.; Cao, J. J.; An, Z. S.; Chow, J. C.; Watson, J. G.; Jin, Z. D.; Fung, K.; Liu, S. X. Evaluation of the thermal/optical reflectance method for quantification of elemental carbon in sediments. Chemosphere 2007, 69 (4), 526-533.

(44) Yang, Z.; Wang, H.; Saito, Y.; Milliman, J. D.; Xu, K.; Qiao, S.; Shi, G. Dam impacts on the Changjiang (Yangtze) River sediment discharge to the sea: The past 55 years and after the Three Gorges Dam. Water Resour. Res. 2006, 42 (4), No. W04407.

(45) Wang, H.; Yang, Z.; Saito, Y.; Liu, J. P.; Sun, X.; Wang, Y. Stepwise decreases of the Huanghe (Yellow River) sediment load (1950-2005): Impacts of climate change and human activities. Global Planet.Change 2007, 57 (3), 331-354.

(46) Guo, Z.; Lin, T.; Zhang, G.; Yang, Z.; Fang, M. HighResolution Depositional Records of Polycyclic Aromatic Hydrocarbons in the Central Continental Shelf Mud of the East China Sea. Environ. Sci. Technol. 2006, 40 (17), 5304-5311.

(47) Hu, L.; Guo, Z.; Shi, X.; Qin, Y.; Lei, K.; Zhang, G. Temporal trends of aliphatic and polyaromatic hydrocarbons in the Bohai Sea, China: Evidence from the sedimentary record. Org. Geochem. 2011, 42 (10), 1181-1193.

(48) Hao, Y. C. Preliminary study on the characters of elemental geochemistry and high resolution sedimentary record in the process of land-sea interaction in the East China. Ph.D. Dissertation, Ocean University of China, Qingdao, China, 2008 [in Chinese].

(49) Zhang, Y.; Dou, H.; Chang, B.; Wei, Z.; Qiu, W.; Liu, S.; Liu, W.; Tao, S., Emission of Polycyclic Aromatic Hydrocarbons from Indoor Straw Burning and Emission Inventory Updating in China. In Environmental Challenges in the Pacific Basin; Carpenter, D. O., Ed.; Annals of the New York Academy of Sciences, Vol. 1140; WileyBlackwell: 2008; pp 218-227.

(50) Wang, R.; Tao, S.; Wang, W.; Liu, J.; Shen, H.; Shen, G.; Wang, B.; Liu, X.; Li, W.; Huang, Y.; et al. Black Carbon Emissions in China from 1949 to 2050. Environ. Sci. Technol. 2012, 46 (14), 7595-7603.

(51) Guo, Z.; Lin, T.; Zhang, G.; Zheng, M.; Zhang, Z.; Hao, Y.; Fang, M. The sedimentary fluxes of polycyclic aromatic hydrocarbons in the Yangtze River Estuary coastal sea for the past century. Sci. Total Environ. 2007, 386 (1), 33-41.

(52) Hao, Y.; Guo, Z.; Yang, Z.; Fan, D.; Fang, M.; Li, X. Tracking historical lead pollution in the coastal area adjacent to the Yangtze River Estuary using lead isotopic compositions. Environ. Pollut. 2008, 156 (3), 1325-1331.

(53) Xu, S.; Liu, W.; Tao, S. Emission of polycyclic aromatic hydrocarbons in China. Environ. Sci. Technol. 2006, 40 (3), 702-708.
(54) Lin, T.; Qin, Y.; Zheng, B.; Li, Y.; Zhang, L.; Guo, Z. Sedimentary record of polycyclic aromatic hydrocarbons in a reservoir in Northeast China. Environ. Pollut. 2012, 163 (0), 256-260.

(55) Cai, M.; Lin, Y.; Chen, M.; Yang, W.; Du, H.; Xu, Y.; Cheng, S.; $\mathrm{Xu}, \mathrm{F}$.; Hong, J.; Chen, M.; Ke, H. Improved source apportionment of $\mathrm{PAHs}$ and $\mathrm{Pb}$ by integrating $\mathrm{Pb}$ stable isotopes and positive matrix factorization application (PAHs): A historical record case study from the northern South China Sea. Sci. Total Environ. 2017, 609, 577586.

(56) Fang, Y.; Chen, Y.; Tian, C.; Lin, T.; Hu, L.; Li, J.; Zhang, G. Application of PMF receptor model merging with PAHs signatures for source apportionment of black carbon in the continental shelf surface sediments of the Bohai and Yellow Seas, China. J. Geophys. Res. 2016, 121 (2), 1346-1359.

(57) Husain, L.; Khan, A.; Ahmed, T.; Swami, K.; Bari, A.; Webber, J. S.; Li, J. Trends in atmospheric elemental carbon concentrations from 1835 to 2005. J. Geophys. Res. 2008, 113, No. D13102.

(58) Gustafsson, Ö.; Haghseta, F.; Chan, C.; MacFarlane, J.; Gschwend, P. M. Quantification of the dilute sedimentary soot phase: Implications for $\mathrm{PAH}$ speciation and bioavailability. Environ. Sci. Technol. 1997, 31 (1), 203-209.

(59) Bogdal, C.; Bucheli, T. D.; Agarwal, T.; Anselmetti, F. S.; Blum, F.; Hungerbuhler, K.; Kohler, M.; Schmid, P.; Scheringer, M.; Sobek, A. Contrasting temporal trends and relationships of total organic carbon, black carbon, and polycyclic aromatic hydrocarbons in rural low-altitude and remote high-altitude lakes. J. Environ. Monit. 2011, 13 (5), 1316-1326.

(60) Han, Y. M.; Bandowe, B. A. M.; Wei, C.; Cao, J. J.; Wilcke, W.; Wang, G. H.; Ni, H. Y.; Jin, Z. D.; An, Z. S.; Yan, B. Z. Stronger association of polycyclic aromatic hydrocarbons with soot than with char in soils and sediments. Chemosphere 2015, 119 (0), 1335-1345. 